\title{
Demographic profile in women undergoing second stage caesarean section
}

\author{
Isha $^{1 *}$, Prabha Lal ${ }^{2}$, Vikram Dutta ${ }^{3}$, Aayushi Kaushal ${ }^{1 *}$
}

\begin{abstract}
${ }^{1}$ Department of Obstetrics and Gynecology, PGIMER, Chandigarh, Punjab, India
${ }^{2}$ Department of Obstetrics and Gynecology, Lady Hardinge Medical Collage, Delhi, India

${ }^{3}$ Department of Pediatrics, Lady Hardinge Medical Collage, Delhi, India
\end{abstract}

Received: 10 November 2019

Revised: 23 December 2019

Accepted: 27 December 2019

\section{*Correspondence:}

Dr. Aayushi Kaushal,

E-mail: kaushalaayushi@gmail.com

Copyright: ( ) the author(s), publisher and licensee Medip Academy. This is an open-access article distributed under the terms of the Creative Commons Attribution Non-Commercial License, which permits unrestricted non-commercial use, distribution, and reproduction in any medium, provided the original work is properly cited.

\begin{abstract}
Background: Incidence of caesarean section is rapidly rising over the last two decades and $25 \%$ is contributed by second stage caesarean section. Demographic factors influencing fetomaternal outcome in second stage caesarean section include BMI, socioeconomic status, booking/ unbooking status, gravidity and maternal height.

Methods: The present study was prospective observational study conducted in the department of obstetrics and gynaecology at Lady Hardanger Medical College New Delhi from December 2015 to March 2017. 80 women were enrolled in the study. A detailed history and examination of each patient was carried out. Women were observed during lab our till second stage caesarean section.

Results: Mean age of population was $25.26 \pm 3.75$ ranging from $19-40$ year. $76.25 \%$ included in study were booked and $11.25 \%$ were unbooked, $42.5 \%$ belonged to lower middle class and $31.25 \%$ belonged to upper middle class. $47 \%$ women had height of $<150 \mathrm{~cm}$ and $70 \%$ had a BMI between $(25-29.9) \mathrm{kg} / \mathrm{m} .43 \%$ women had gestational age between 39-40 weeks.

Conclusions: Second stage caesarean section was more common in young age group and primigravidae. Higher BMI was not only operative but obstetrical risk as well.
\end{abstract}

Keywords: Demographic factors, Raised body mass index, Second stage caesarean

\section{INTRODUCTION}

Incidence of caesarean section is rapidly rising over the last two decades ranging from $0.4-42.3 \% .^{1,2}$ Second stage caesarean section contributes to $25 \%$ of all caesarean section done. ${ }^{3}$ There are demographic factors which influence the fetomaternal outcome in second stage caesarean section includes BMI, socioeconomic status, booking/ unbooking status, gravidity and maternal height. Neonatal mortality and morbidity due to hypoxia and fetal trauma remains to be one of the major issues regarding the caesarean section performed in the second stage of labour. ${ }^{4}$ Thus the rising rate of caesarean section at full cervical dilatation is not only a concern for the delivery in question but it also may have negative impact on women's future pregnancy and deliveries. ${ }^{5}$

Objective of this study was to study demographic profile in women undergoing second stage caesarean section.

\section{METHODS}

The present study was prospective observational study conducted in the department of obstetrics and 
gynaecology at Lady Hardinge Medical College and Smt. Sucheta Kriplani Hospital, New Delhi from December 2015 to March 2017. After clearance from institutional ethical committee, 80 women were enrolled in the study after fulfilling the inclusion and exclusion criteria. Inclusion criteria includes all uncomplicated term pregnancy with period of gestation, singleton pregnancy with cephalic presentation in second stage of labour. Exclusion criteria are women not giving consent, intrauterine death, multiple pregnancy, gross congenital anomaly and with medical disorders like DM, HTN, prev-LSCS, APH, anaemia.

A detailed history of each patient was carried out including chief complaints, LMP, EDD, onset of labour pains, presence of LPV and referral from other hospital. Baseline maternal data with regard to age, parity, POG, demographic data, BMI recorded. Through history was taken to rule out any other systemic illness. Period of gestation was calculated from LMP and confirmed by ultrasonography. This was followed by general physical examination, systemic examination and obstetric palpation and pelvic examination as per Performa. The vitals of women including pulse rate, blood pressure, height, weight, and BMI were recorded. Relevant investigations as per protocol of the department were done in predesigned format. A partographic management of labour was done. Women were observed during labour and followed till caesarean section in second stage of labour.

\section{RESULTS}

Total number of deliveries during this period was 22014 , out of which NVD were 17165 and caesarean deliveries were 4849 . Thus, caesarean section rate was $22 \%$ out of which $3.9 \%$ caesarean sections were done in second stage of labour. Second stage CS compared to $1^{\text {st }}$ stage is associated with increased complications.

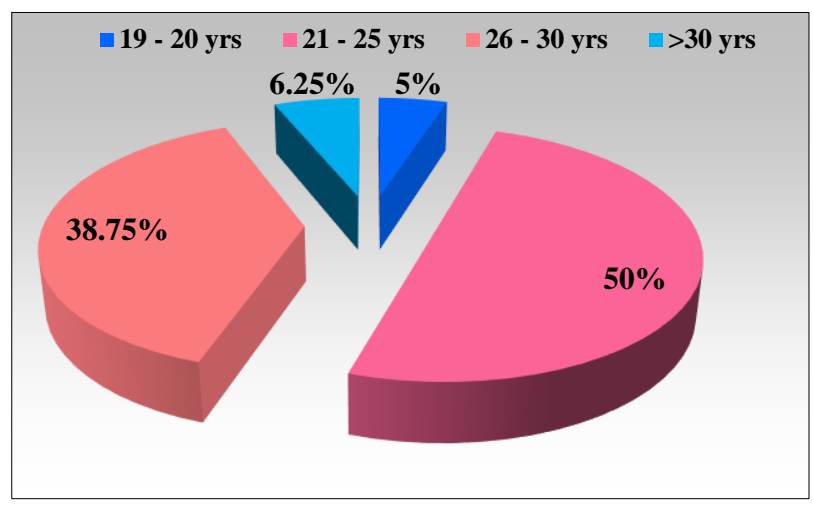

Figure 1: Distribution of women according to age group.

Figure 1 show that mean age of population was $25.26 \pm 3.75$ ranging from $19-40$ year. $50 \%$ were between age group $21-25$ years, $38.75 \%$ were between age group
26-30 years, $6.25 \%$ had age group $>30$ years and $5 \%$ had age group 19-20 years.

As shown in (Table 1), 61 out of 80 women $(76.25 \%)$ included in study were booked and 9 out of 80 women $(11.25 \%)$ were unbooked. 10 out of 80 women $(12.5 \%)$ were referred second stage of labour with full dilatation of cervix.

Table 1: Distribution of women according to booking and referral status.

\begin{tabular}{|lll|}
\hline $\begin{array}{l}\text { Booked / unbooked / } \\
\text { referred }\end{array}$ & $\begin{array}{l}\text { Number of } \\
\text { women (n) }\end{array}$ & $\%$ \\
\hline Booked* & 61 & $76.25 \%$ \\
\hline Unbooked & 9 & $11.25 \%$ \\
\hline Referred & 10 & $12.5 \%$ \\
\hline Total & $\mathbf{8 0}$ & $\mathbf{1 0 0 \%}$ \\
\hline
\end{tabular}

*A woman was considered to be booked on having at least 3 antenatal visits.

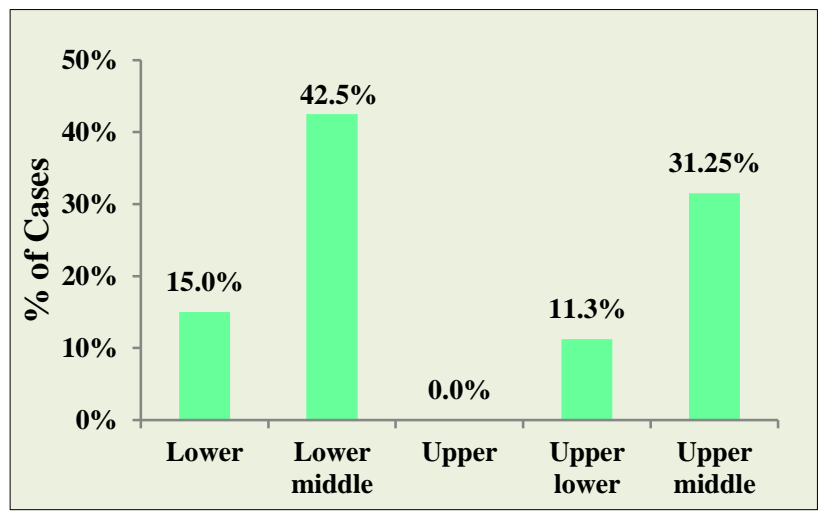

Figure 2: Distribution of women according to socioeconomic status.

Figure 2 shows distribution of women according to socioeconomic status as per modified Kuppuswamy classification. It was observed that $42.5 \%$ belonged to lower middle class and $31.25 \%$ belonged to upper middle class, $15 \%$ belonged to lower class and $11.3 \%$ belonged to upper lower class.

Table 2: Distribution of women according to gravidity.

\begin{tabular}{|lll|}
\hline Gravidity & Number of women (n) & $\%$ \\
\hline G1 & 50 & $62.5 \%$ \\
\hline G2, G3 & 29 & $36.25 \%$ \\
\hline G4 $\geq$ & 1 & $1.25 \%$ \\
\hline Total & $\mathbf{8 0}$ & $\mathbf{1 0 0 \%}$ \\
\hline
\end{tabular}

As it is shown in (Table 2) that maximum number of women 50 out of $80(62.5 \%)$ were primigravidae and $36.25 \%$ were $2^{\text {nd }}$ and $3^{\text {rd }}$ gravida. Only $1.25 \%$ women were G4 
Table 3 shows $8.75 \%$ of women were illiterate, $23.75 \%$ of women had education level of primary, $36.25 \%$ had an education level of higher secondary and $31.25 \%$ were graduate.

\section{Table 3: Distribution of women according to} education status.

\begin{tabular}{|lll|}
\hline Education level & Number of women (n) & $\%$ \\
\hline Illiterate & 7 & 8.75 \\
\hline Primary & 19 & 23.75 \\
\hline Higher secondary & 29 & 36.25 \\
\hline Graduate & 25 & 31.25 \\
\hline Total & $\mathbf{8 0}$ & $\mathbf{1 0 0}$ \\
\hline
\end{tabular}

Table 4: Distribution of women according to the height.

\begin{tabular}{|lll|}
\hline Height $(\mathbf{c m})$ & Number of women $(\mathbf{n})$ & $\%$ \\
\hline$\leq 150$ & 38 & 47.5 \\
\hline $151-155$ & 30 & 37.5 \\
\hline $156-160$ & 10 & 12.5 \\
\hline$>160$ & 2 & 2.5 \\
\hline Mean \pm SD & $152.14 \pm 3.7$ & \\
\hline Range & $147-161 \mathrm{~cm}$ \\
\hline
\end{tabular}

Table 4 shows that the mean height of the total population was $152.14 \pm 3.7 \mathrm{~cm}$ ranging between 147 to $161 \mathrm{~cm}$. Out of 80 women from the study group 38 women $(47.5 \%)$ had height less than $150 \mathrm{~cm}$. Whereas 30 women $(37.5 \%)$ had height between $151-155 \mathrm{~cm}, 10$ women $(12.5 \%)$ had height of $156-160 \mathrm{~cm}$ and 2 women $(2.5 \%)$ had a height of $>160 \mathrm{~cm}$.

Table 5: Distribution of the women according to the BMI.

\begin{tabular}{|lll|}
\hline BMI & Number of women (n) & $\%$ \\
\hline$<18.5$ & 0 & 0 \\
\hline $18.5-24.9$ & 13 & $16.2 \%$ \\
\hline $25-29.9$ & 56 & $70 \%$ \\
\hline$\geq 30$ & 11 & $13.8 \%$ \\
\hline Total & $\mathbf{8 0}$ & $\mathbf{1 0 0 \%}$ \\
\hline Mean \pm SD & $27.19 \pm 2.26$ & \\
\hline Range & $21.6-31.2 \mathrm{~cm}$ & \\
\hline
\end{tabular}

A total $47.5 \%$ women had a height $<150 \mathrm{~cm}$, as majority of women were of short height suggesting that short height is the risk factor for women in labour who require second stage caesarean section

On analysing (Table 5) it was observed that mean BMI was 27.19 \pm 2.26 and ranged from 21.6-31.2. 70\% had a BMI between $(25-29.9) \mathrm{kg} / \mathrm{m}^{2}$ and $13.8 \%$ had a BMI $\geq$ 30. $16.2 \%$ had BMI between 18.5-24.9.

On analysing (Figure 3) it was found out that 11 women out of 80 were of gestational age $<38$ weeks, 20 women had gestational age of 38-39 weeks, 35 women belonged to gestational age of $39-40$ weeks, 12 women had gestational age between 40-41 weeks and only 2 women had gestational age of $>41$ weeks.

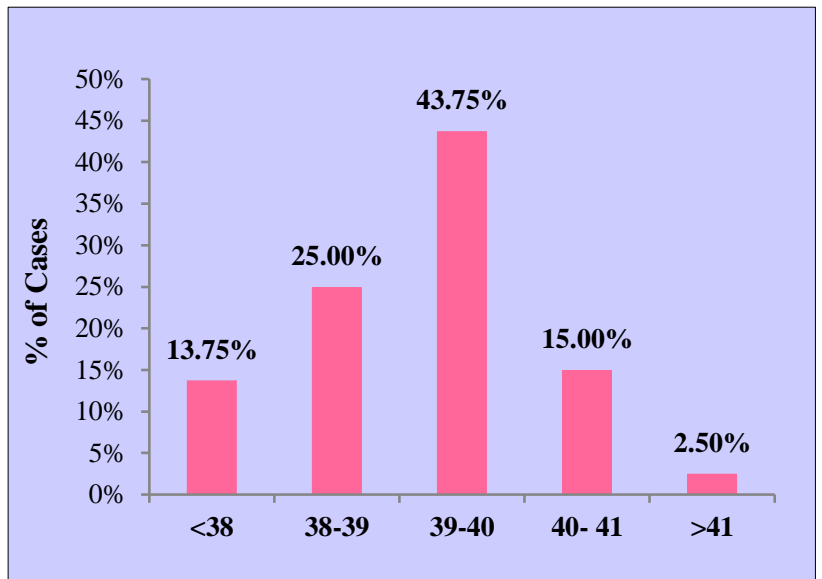

Figure 3: Distribution of women according to gestational age.

\section{DISCUSSION}

The present prospective observational study conducted in the department of obstetrics and gynaecology at Lady Hardinge Medical College New Delhi from December 2015 to March 2017.

Caesarean section rate was $22 \%$ out of which $3.9 \%$ caesarean sections were done in second stage of labour.

Table 6: Age and parity of women in other studies.

\begin{tabular}{|lllll|}
\hline & & & Gravidity & \\
\hline Authors & Number of cases & Mean maternal age in (years) & Primi & Multi \\
\hline Moodley ${ }^{6}$ et al & 53 & $23.79 \pm 5.7$ & $70 \%$ & $30 \%$ \\
\hline Asicioglu ${ }^{7}$ et al & 298 & $27.5 \pm 2.9$ & - & - \\
\hline Alexender ${ }^{8}$ et al & 2716 & $26.7 \pm 6.4$ & $74 \%$ & $26 \%$ \\
\hline Malathi $\mathrm{J}^{9}$ et al & 50 & - & $74 \%$ & $26 \%$ \\
\hline Jain et al $^{10}$ & 50 & - & $80 \%$ & $20 \%$ \\
\hline Present study & 80 & $25.26 \pm 3.75$ & $63 \%$ & $37 \%$ \\
\hline
\end{tabular}


Table 6 shows mean maternal age and gravidity in present study and in different studies. In the present study, the mean age was $25.26 \pm 3.75$ years which were comparable to the studies by Moodley et al, Asicioglu et al, and Alexender et al, $(27.5 \pm 2.9$ years $){ }^{6-8}$ The reason for having younger women in the study could be due to early age of marriage and this reproductive age group being most fertile group.

A total $62.5 \%$ of women were primigravidae which is almost comparable to studies done by Malathi $\mathrm{J}$ et al, and Jain et al. ${ }^{9,10}$ This could be due to various reasons such as inability to diagnose occipito posterior position and CPD at an early stage of labour by attending obstetrician. Lack of experience of previous labour in this group of women could also be another reason, thus predisposing them to have more of dysfunctional labour.

A total $57.5 \%$ of women belonged to lower class, out of which majority $42.5 \%$ were lower middle and $15 \%$ lower. Women belonging to lower class have poor compliance for antenatal visit and institutional delivery thus attending hospital at a very late and advanced stage of labour with either impending obstruction or in a state of obstructed labour.

A total $36.25 \%$ women were educated up to higher secondary level and $31.25 \%$ had an education level of graduation. In the present study level of education was not found to have any relationship with second stage caesarean section.

Total number of booked patients were $76.25 \%$, unbooked were $11.25 \%$ and referred patients were $12.5 \%$. Unbooked and referred patients were more prone to have increased maternal and fetal morbidity as compared to booked patients. Referred patients were also unbooked and presented in our centre in the advanced labour with obstruction and had complication of bladder injury 30\%, extension of incision in 55\%, $\mathrm{PPH}$ in $50 \%$, blood transfusion in $30 \%$ and still birth in $1.25 \%$.

In this present study majority of women had BMI between $25-29.9 \mathrm{~kg} / \mathrm{m}^{2}$ and $13.8 \%$ had BMI of $\geq 30$ which was comparable to the study done by Sucak et al, Prameela et al, and Das S et al. ${ }^{11-13}$ Thus it appears that obesity is not only an operative risk factor but also an obstetric risk factor as well.

The importance of height as an index of pelvic adequacy and moreover of reproductive efficiency has been studied by Baird. ${ }^{14}$ According to this study as the height of mother decreases, the rate of caesarean section rises. He had shown that reproductive performance is best in women who are $162 \mathrm{~cm}$ or more in height.

In the present study the gestational age of women undergoing second caesarean section was ranged from 37 weeks to $41 \pm 3$ which is almost comparable to the study done by Allen VM et al, Moodley et al, Asicioglu et al, and Das S et al. ${ }^{3,6,7,13}$ Another study done by Mckelvey et al, found that women undergoing second stage caesarean section had gestational age $>41$ weeks indicating as the gestational age and maturity increases, risk for caesarean section may also increase due to fetal head maturity thus interfering in physiological moulding process during labour leading to CPD. ${ }^{15}$

\section{CONCLUSION}

Second stage caesarean section was more common in young age group due to this reproductive age group being most fertile. Incidence was more common in primigravidae than multigravida due to uterine inertia, undiagnosed CPD and lack of experience of previous labour.

Two third women belonged to lower socioeconomic status. $47 \%$ of women had height of $<150 \mathrm{~cm}$ having high risk for going to second stage caesarean section. $70 \%$ had BMI between $25-29.9 \mathrm{~kg} / \mathrm{m}^{2}$. Thus, higher BMI is not only the operating risk but obstetrical risk as well.

\section{Funding: No funding sources}

Conflict of interest: None declared

Ethical approval: The study was approved by the Institutional Ethics Committee

\section{REFERENCES}

1. Martin A, Hamilton BE, Ventura SJ, Osterman MJ, Kirmeyer S, Maathews TJ, et al. Birth: final data for 2009. Natl Vital Stat Rep. 2011;60:1-70.

2. Zizza A, Tinelli I, Malvasi A, Barbone E, Stark M, Guido M, et al. Caesarean sections in the World: a new ecological approach. J Prevent Med Hyg. 2011;52:4.

3. Allen VM, O'Connell CM, Basket TF. Maternal morbidity associated with caesarean delivery without labour compared with spontaneous onset of labour at term. Int J Gynaecol Obstet. 2003;102:477-82.

4. Seal SL, Kamilya G, Mukherji J, Bhattacharya SK, Harza A. Outcome in second- versus first stage caesarean delivery in a teaching institution in Eastern India. Am J Perinatol. 2010;27:507-12.

5. Unterscheider J, Menamin M, Cullinane F. Rising rates of cesarean deliveries at full cervical dilatation: a concerning trend. Eu J Obstet Gynecol Repro Biol. 2011;157:141-4.

6. Moodley J, Devjee J, Khedun SM, Esterhuizen T. Second-stage primary caesarean deliveries: are maternal complications increased. SA Fam Pract. 2009;51(4):328-31.

7. Asicioglu O, Gungorduk K, Yildrim G, Cemal A. Second stage versus first stage caesarean delivery comparison of maternal and perinatal outcomes. J Obstet Gynecol. 2014;1:7.

8. Alexander, James M, Kenneth J, Leveno, Rouse, Dwight $\mathbf{J}$, et al. Comparison of maternal and infant outcomes from primary caesarean delivery during the 
second compared with first stage of labour. Am J Obstet Gynecol. 2007;109:917-21.

9. Malathi J, Venigalla S. Comparison of obstetric outcome between first and second stage caesarean sections in rural tertiary hospital. Int $\mathbf{J}$ Pharma Biomed Res. 2012;3(4):222-5.

10. Jain N, Lal P. A retrospective comparative study of feto-maternal outcome in first and second stage caesarean section. Int $\mathrm{J}$ Reprod Contracep Obstet Gynecol. 2016;5(7):2282.

11. Sucak A, Celen S, Akbaba E, Soysal S, Moraloglu O, Danisman N. Comparison of nulliparous undergoing caesarean section in first and second stages of labour. Obstet Gynaecol Int. 201;4.

12. Prameela. Comparison of obstetric and neonatal outcome between first and second stage caesarean sections in Tertiary Hospital MMC and RI, Mysore. Int J Recent Trends Sci Technol. 2015;14(3):520-2.
13. Das S, Sarkar SK. Fetomaternal outcome in second versus first stage caesarean delivery in a tertiary rural medical collage. IOSR J Dent Med Sci. 2014;13(12):28-30.

14. Baird D. Dystocia due to faults in the pelvis. Br J Obstet Gynaecol. 1985;92:1235-45.

15. Mckelvey A, Ashe R, Mckenna D, Roberts. Caesarean section in second stage of labour: retrospective view of obstetric setting and morbidity. J Obstet Gynaecol. 2010;30(3):264-7.

Cite this article as: Isha, Lal P, Dutta V, Kaushal A. Demographic profile in women undergoing second stage caesarean section. Int J Reprod Contracept Obstet Gynecol 2020;9:570-4. 